\section{Differences in central corneal thickness between the paired eyes and the severity of the glaucomatous damage}

${ }^{1}$ Laboratorio clinico anatomo-funzionale per la diagnosi e il trattamento del glaucoma e delle malattie neurooftalmologiche, Clinica Oculistica, Department of Neurological Sciences, Ophthalmology, Genetic, University of Genoa, Genoa, Italy

${ }^{2}$ Clinica Oculistica, University of Siena, Siena, Italy

${ }^{3}$ Clinica Oculistica, University Tor Vergata, Rome, Italy

${ }^{4}$ Clinica Oculistica, University of Catania, Catania, Italy

${ }^{5}$ Clinica Oculistica, University of Pisa, Pisa, Italy

${ }^{6}$ Clinica Oculistica, University of La Sapienza II, Rome, Italy

Correspondence:

$M$ lester, University Eye Clinic, Viale Benedetto XV, 5, Genoa 16132, Italy Tel: + 390103537783 Fax: + 390103538494 E-mail: iester@unige.it

${ }^{7}$ See Appendix

Received: 2 November 2011 Accepted in revised form:

9 July 2012

Published online:

14 September 2012

This study has been presented in part at Association for Research and Vision in Ophthalmology (ARVO) meeting 1-5 May 2011, in Ft Lauderdale, FL, USA.

\begin{abstract}
Purpose To evaluate whether a difference in central corneal thickness (CCT) between the paired eyes could be associated to worse glaucoma in the thinner cornea eye. Methods From 16 different glaucoma centres, at least 50 glaucomatous patients were saved on the Italian Glaucoma Register. Eight hundred and sixteen glaucomatous patients were found in the register. CCT, ophthalmoscopic cup/disc ratio, mean deviation (MD), pattern SD (PSD), and intraocular pressure (IOP). The difference $(\Delta)$ between the paired eyes was calculated for all the considered parameters and two subgroups were created on the basis of $\triangle \mathrm{CCT}$. Because the difference between the two eyes could be positive or negative, the absolute value of $\Delta$ was considered for all the measurements. Three different $\triangle \mathrm{CCT}$ cutoffs were selected: 10, 15 , and $20 \mu \mathrm{m}$. Student's $t$-test was used to compare the subgroups.

Results When the entire group was divided in two subgroups using $20 \mu \mathrm{m}$ as $\Delta$ CCT cutoff, no significant difference was found for $\triangle \mathrm{IOP}$ $(-0.38 \pm 2.53$ (mean \pm SD) $\mathrm{mm} \mathrm{Hg}$ and $-0.07 \pm 2.35 \mathrm{~mm} \mathrm{Hg}$, respectively) between the two subgroups. Significant $(P<0.001)$ difference was found for $\triangle \mathrm{MD}(6.58 \pm 7.30$ and $3.14 \pm 4.22 \mathrm{~dB}$, respectively), $\triangle \mathrm{PSD}(3.92 \pm 4.01$ and $2.16 \pm 2.57$, respectively), and $\Delta \mathrm{C} / \mathrm{D}$ $(0.11 \pm 0.14$ and $0.08 \pm 0.11$, respectively) between the two subgroups. No significant correlation was found between $\triangle \mathrm{CCT}$ and the other parameters.

Conclusion The $\triangle \mathrm{CCT}$ between the two eyes could be associated to a worse glaucoma in the thinner cornea eye.
\end{abstract}

M lester ${ }^{1}$, S Telani ${ }^{1}$, P Frezzotti², G Manni ${ }^{3}$, M Uva', M Figus ${ }^{5}$, A Perdicchi $^{6}$ and the Italian Glaucoma Register
Eye (2012) 26, 1424-1430; doi:10.1038/eye.2012.179; published online 14 September 2012

Keywords: glaucoma; central corneal thickness; visual field damage; difference between eyes

\section{Introduction}

As glaucoma is a chronic asymmetric progressive degenerative disease of the optic nerve head, most patients with glaucoma can have a different stage of the disease between the two eyes.

Although central corneal thickness (CCT) measurements are usually highly symmetric between paired eyes, approximately $6-7 \%$ of individuals do manifest significant interocular CCT asymmetry. ${ }^{1-3}$ CCT has been identified as a substantial glaucoma risk factor, $^{4-8}$ and glaucomatous damage often presents in an asymmetric fashion.9,10 The percentage of normal-tension and hightension glaucoma patients with unilateral VF loss has been estimated to be approximately $25-35 \%{ }^{9}$

Asymmetric CCT was already associated with asymmetric primary open-angle glaucoma (POAG) in a retrospective study. ${ }^{11}$ In a later study by the same group, however, asymmetric POAG was associated with asymmetric dynamic contour tonometry but not Goldmann applanation tonometry or CCT. ${ }^{12}$

The aim of the study was to evaluate whether a difference in CCT between paired eyes could be associated to worse glaucoma in the thinner cornea eye. 


\section{Patients and methods}

This is a retrospective, cross-sectional study. Institutional review boards and ethics committees at the institutions gave their approval of this study. This study followed the principles of the Declaration of Helsinki.

From 16 different glaucoma centres, at least 50 glaucomatous patients for each centre were saved on the Italian Glaucoma Register (IGR). Glaucomatous eyes were diagnosed based upon having a reproducible and characteristic VF defect of three non-edge points, all of which were depressed on the pattern deviation plot at a $P<5 \%$, along with an asymmetrical cupping $>0.2$, the presence of a notch on the rim and/or an increased cupping $>0.6$ when measured as cup/disc ratio (CDR) and an open angle at gonioscopy.

All subjects underwent at least two Swedish interactive thresholding algorithm (SITA) standard 24-2 perimetry. Reliable tests had $<30 \%$ fixation losses, false-negative and false-positive responses. Patients included in this study had a best-corrected visual acuity of $20 / 60$ or better and a refractive error of +6.00 to -6.00 dioptres. Subjects were excluded for a history of diabetes or posterior pole pathology other than glaucoma. In addition, subjects were excluded for use of systemic steroids, any other systemic medication known to affect the retina, any neurological condition known to affect the VF, and any ocular surgery.

The diagnosis of glaucoma was based on visual field examination, optic nerve head analysis, intraocular pressure (IOP) measurements, and gonioscopy. ${ }^{13}$

CCT was measured with ultrasonic contact pachymeter. Pachymetry values were always obtained by the same observer in all the different centres. Patients were instructed to look straight ahead at a fixation target located at $3 \mathrm{~m}$. After having pushed the button to initiate corneal thickness measurements, the probe tip was gently positioned to touch the patient's cornea at its centre. The pachymeter probe had to be perpendicular to the apex of the cornea. If the measurement was valid, a value appeared on the digital display. The mean value of three consecutive measurements was used for the statistical analysis.

CCT, ophthalmoscopic CDR, mean deviation (MD), pattern standard deviation (PSD), and IOP were considered in this study. Besides the difference $(\Delta)$ between the paired eyes was calculated for all the considered parameters. Because the difference was always calculated as 'Right-Left', an absolute value was introduced to avoid negative values and to better analyse the difference in the group. Then two subgroups were created on the basis of the absolute $\triangle C C T$ and three different cutoffs were arbitrarily chosen to perform the analysis: 10,15 , and $20 \mu \mathrm{m}$.
The data were analysed by descriptive analysis and when the distribution of the data was normal, $t$-test and Pearson's $r$ coefficient were used and when the distribution of the data was non-normal, Mann-Whitney test and Spearman's coefficient were used.

\section{Results}

Eight hundred and sixteen patients were included in the IGR. Twenty-two patients were excluded because the CCT measurement was present for only one eye: five patients had only right measurements and ten only left measurements, and seven patients did not have the VF data for both eyes. All the patients were Caucasian. The descriptive analysis of the 794 included patients has been described in Table 1. No significant difference was found between paired eyes for IOP, CDR, MD, PSD, and CCT (Table 2). The distribution curves for CCT of both eyes and distribution of the CCT asymmetry between paired eyes have been shown in Figures 1a-c.

Then the entire group was divided into two subgroups based on the magnitude of absolute $\triangle \mathrm{CCT}$ between the two eyes. When the cutoff between the two subgroups was $10 \mu \mathrm{m}$, no significant difference was found for IOP, CDR, RPSD, LPSD, and $\triangle$ PSD, whereas a significant difference was found for RMD, LMD, absolute $\triangle \mathrm{MD}$, and absolute $\triangle$ PSD (Table 3 ).

Table 1 Descriptive analysis of 794 patients

\begin{tabular}{lrr}
\hline & Mean & \multicolumn{1}{c}{$S D$} \\
\hline Age (year) & 65.52 & 12.78 \\
Right IOP $(\mathrm{mm} \mathrm{Hg})$ & 16.16 & 3.55 \\
Left IOP $(\mathrm{mm} \mathrm{Hg})$ & 16.28 & 3.31 \\
$\Delta \mathrm{IOP}(\mathrm{mm} \mathrm{Hg})$ & -0.12 & 2.38 \\
Absolute $\Delta \mathrm{IOP}(\mathrm{mm} \mathrm{Hg})$ & 1.45 & 1.90 \\
Right CDR & 0.55 & 0.21 \\
Left CDR & 0.56 & 0.21 \\
$\Delta$ CDR & -0.01 & 0.15 \\
Absolute $\Delta \mathrm{CDR}$ & 0.87 & 0.11 \\
Right CCT $(\mu \mathrm{m})$ & 545.68 & 35.82 \\
Left CCT $(\mu \mathrm{m})$ & 546.89 & 36.09 \\
$\Delta$ CCT $(\mu \mathrm{m})$ & -1.22 & 15.44 \\
Absolute $\Delta$ CCT $(\mu \mathrm{m})$ & 10.41 & 11.46 \\
Right MD $(\mathrm{dB})$ & -5.23 & 6.38 \\
Left MD $(\mathrm{dB})$ & -5.37 & 6.58 \\
$\Delta$ MD $(\mathrm{dB})$ & 0.14 & 6.22 \\
Absolute $\Delta \mathrm{MD}(\mathrm{dB})$ & 3.70 & 5.00 \\
Right PSD & 4.53 & 3.61 \\
Left PSD & 4.49 & 3.49 \\
$\Delta$ PSD & 0.04 & 3.81 \\
Absolute $\Delta \mathrm{PSD}$ & 2.45 & 2.92 \\
\hline Abbevi & &
\end{tabular}

Abbreviations: $\mathrm{CCT}$, central corneal thickness; $\mathrm{CDR}$, cup/disc area ratio; $\Delta$, difference; IOP, intraocular pressure; MD, mean deviation; PSD, pattern SD. 
When the cutoff between the two subgroups was $15 \mu \mathrm{m}$, a significant difference was found for absolute $\Delta$ of CDR, RMD, LMD, absolute $\triangle \mathrm{MD}$, RPSD, LPSD, and absolute PSD $\Delta$ (Table 3).

When the cutoff between the two subgroups was $20 \mu \mathrm{m}$, a significant difference was found for absolute $\Delta$ of CDR, RMD, LMD, absolute $\triangle \mathrm{MD}$, RPSD, LPSD, and absolute $\triangle$ PSD (Table 3).

Nonsignificant correlation was found between absolute $\Delta \mathrm{CCT}$ and $\Delta \mathrm{IOP}, \Delta \mathrm{CDR}$, absolute $\Delta \mathrm{CDR}, \Delta \mathrm{MD}$,

Table 2 Comparison between the paired eyes

\begin{tabular}{lrrc}
\hline & Mean & SD & $\begin{array}{c}\text { P-value between } \\
\text { the two eyes }\end{array}$ \\
\hline Right CCT $(\mu \mathrm{m})$ & 545.68 & 35.82 & \\
Left CCT $(\mu \mathrm{m})$ & 546.89 & 36.09 & NS \\
Right CDR & 0.55 & 0.21 & \\
Left CDR & 0.56 & 0.21 & NS \\
Right MD $(\mathrm{dB})$ & -5.23 & 6.38 & \\
Left MD $(\mathrm{dB})$ & -5.37 & 6.58 & NS \\
Right PSD & 4.53 & 3.61 & \\
Left PSD & 4.49 & 3.49 & NS \\
Right IOP $(\mathrm{mm} \mathrm{Hg})$ & 16.16 & 3.55 & \\
Left IOP $(\mathrm{mm} \mathrm{Hg})$ & 16.28 & 3.31 & NS \\
\hline
\end{tabular}

Abbreviations: $\mathrm{CCT}$, central corneal thickness; $\mathrm{CDR}$, cup/disc area ratio; IOP, intraocular pressure; MD, mean deviation; PSD, pattern SD.

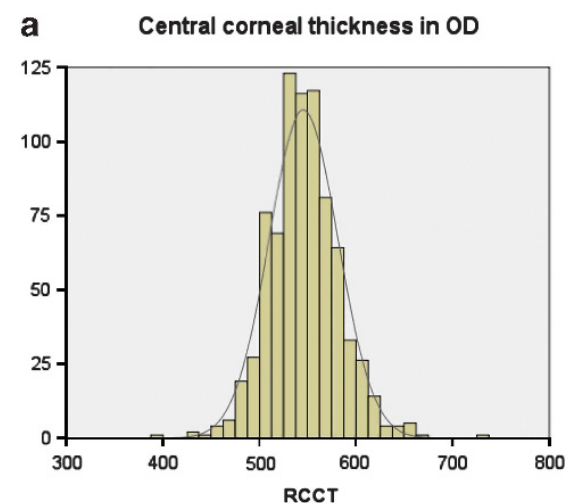

and $\triangle$ PSD. Significant but weak correlation was found for the absolute $\triangle \mathrm{MD}$, for which a weak correlation was found when all the patients were considered and in two subgroups; less and greater than $10 \mu \mathrm{m}$, but no significant correlation was found in the other subgroups: greater than 15 and $20 \mu \mathrm{m}$. Similar results were found for absolute $\triangle$ PSD, but weaker (Table 4).

\section{Discussion}

Glaucoma is an asymmetric disease and in many patients visual field shows significant difference between the two eyes. Also the asymmetry between the right and left optic nerve head of the same subject is considered to be an important predictor of the disease. ${ }^{14}$ Progressive optic disc cupping has been shown to precede visual field loss in patients with $\mathrm{OH},{ }^{15,16}$ and in unilateral glaucoma. ${ }^{17}$ The asymmetry of the CDR between the two eyes has been shown by some but not all studies to predict the development of glaucomatous visual field loss in patients with elevated IOP. ${ }^{18-20}$ Clinically, asymmetry in certain optic disc parameters between the two eyes might assist in differentiating patients with glaucoma from those without glaucoma. In particular, an asymmetry of CDR $>0.2$ between the two eyes can be suspicious of
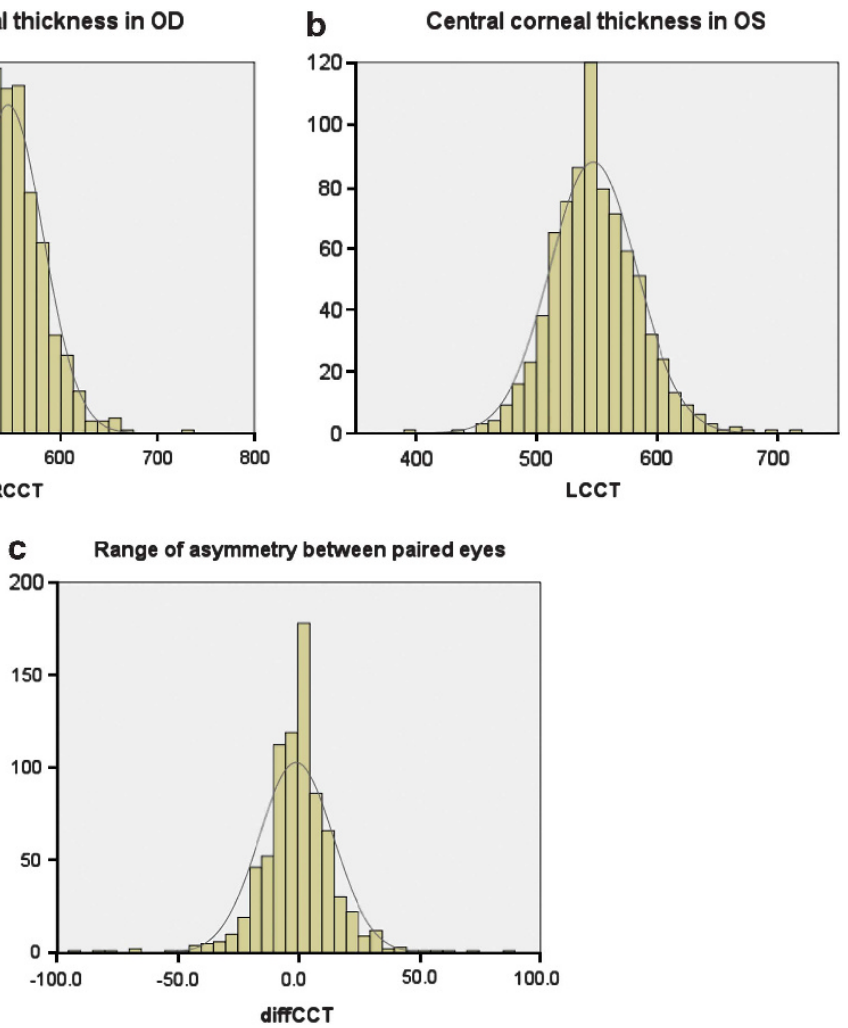

Figure 1 Distribution curve of central corneal thickness (CCT) for the right eye (R) (a) and left eye (L) (b) and of the central corneal thickness difference (diffCCT) between the paired eyes obtained by using the following formula: 'Right-Left' (c). 
Table 3 Comparison between subgroups based on different absolute $\Delta$ CCT cutoffs

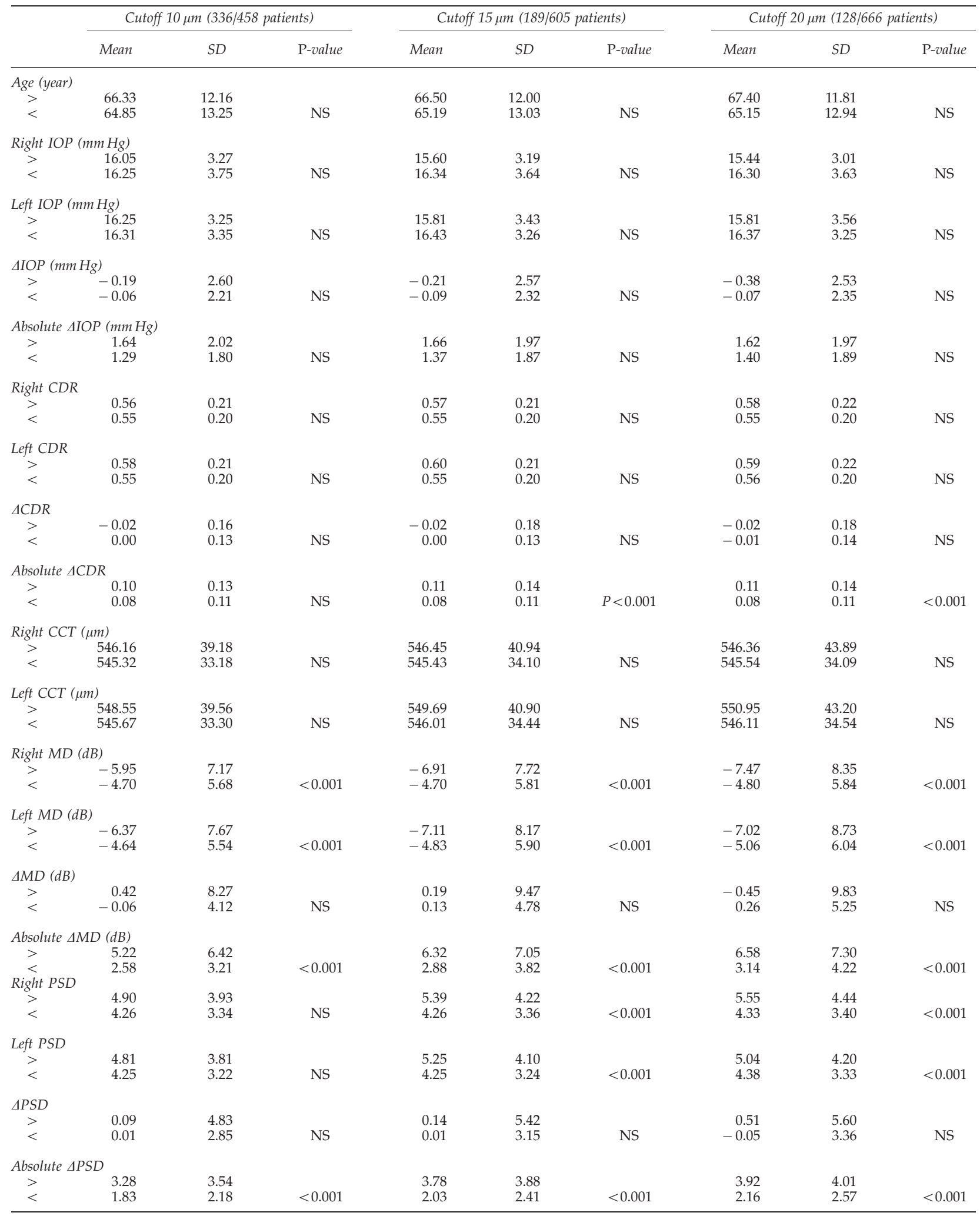

Abbreviations: CCT, central corneal thickness; CDR, cup/disc area ratio; $\Delta$, difference; IOP, intraocular pressure; MD, mean deviation; PSD, pattern SD. 
glaucoma. ${ }^{13}$ Even with the new imaging device the asymmetry is one of the parameter that the computerized systems are able to calculate and are useful to interpret the results of the printout.

The importance of CCT and anterior corneal curvature is known because the flatter the cornea, the easier the applanation to the accuracy of IOP measurement by Goldmann applanation. In clinical practice, many ophthalmologists have begun to routinely measure $\mathrm{CCT}$, and large variations in corneal thickness have been documented, with the expected result. The aim of this study was to evaluate whether a difference in CCT between paired eyes could be correlated to a worse glaucoma. CCT has been shown to be an independent risk factor for glaucoma, ${ }^{4}$ and the relationship between pachymetry values and the risk of glaucoma damage is still controversial. No correlation between the thickness of the central cornea, of the peripapillary retinal nerve fibres $^{21}$ and of the lamina cribrosa ${ }^{22}$ was found in nonglaucomatous human eyes; it is not known whether hystomorphometry of the lamina cribrosa or peripapillary nerve fibre layer thickness in glaucomatous eyes would show a relationship with corneal thickness. There is no consensus on the influence of pachymetry values on the likelihood of progression of glaucomatous damage in established glaucoma. Kim and $\mathrm{Chen}^{23}$ and Herndon $e a^{6}$ proved the association of thinner central cornea values with VF progression in glaucoma patients. Jonas et $a l^{7}$ and Chauhan et $\mathrm{al}^{24}$ found an association between lower CCT and worse baseline VF, but the lower CCT was not associated with the progression of glaucomatous optic nerve neuropathy.

The reliability of central corneal thickness measurement has been much less controversial than that of IOP measurements. ${ }^{25}$ Techniques to measure CCT include optical (mean CCT $530 \mathrm{~mm}$ ) and ultrasound (mean CCT $544 \mathrm{~mm}$ ), with the latter being easier to perform. Also corneal hysteresis might also interfere with IOP measurements; it appears as though this corneal variable describes the response of the cornea to rapid deformation. Congdon $e t a^{26}$ suggested that the relationship between glaucoma and corneal features was more complex than simple anatomic thickness.

Circardian fluctuations in CCT have been found; they were small and, although statistically significant, did not seem to interfere with the circardian IOP measurements. However, no evidence that the 24-h change in IOP was due to the change in corneal biomechanical properties, was shown. ${ }^{27,28}$

In this study, the CCT difference between paired eyes was analysed and the results suggested that a CCT difference $>10 \mu \mathrm{m}$ between the two eyes, could be associated to a worse glaucoma in the thinner cornea eye. However, the weak correlation we found, outlining that

Table 4 Correlation between absolute $\triangle \mathrm{CCT}$ and the other parameters in different subgroups

\begin{tabular}{|c|c|c|c|c|c|}
\hline & All the patients & Abs $\triangle C C T<10 \mu \mathrm{m}$ & Abs $\triangle C C T>10 \mu m$ & Abs $\triangle C C T>15 \mu \mathrm{m}$ & Abs $\triangle C C T>20 \mu m$ \\
\hline \multicolumn{6}{|c|}{$\triangle I O P(m m H g)$} \\
\hline & -0.02 & 0.02 & 0.00 & 0.01 & 0.07 \\
\hline$P$-value & NS & NS & NS & NS & NS \\
\hline \multicolumn{6}{|c|}{ Absolute $\triangle I O P(\mathrm{~mm} \mathrm{Hg})$} \\
\hline & 0.09 & -0.02 & 0.06 & 0.07 & 0.12 \\
\hline$P$-value & NS & NS & NS & NS & NS \\
\hline \multicolumn{6}{|l|}{$\triangle C D R$} \\
\hline & -0.02 & 0.03 & 0.01 & 0.06 & 0.05 \\
\hline$P$-value & NS & NS & NS & NS & NS \\
\hline \multicolumn{6}{|c|}{ Absolute $\triangle C D R$} \\
\hline & 0.09 & 0.09 & 0.03 & -0.08 & -0.10 \\
\hline$P$-value & 0.02 & NS & NS & NS & NS \\
\hline \multicolumn{6}{|l|}{$\triangle M D(d B)$} \\
\hline & -0.04 & -0.12 & -0.10 & -0.11 & -0.09 \\
\hline$P$-value & NS & 0.01 & NS & NS & NS \\
\hline \multicolumn{6}{|c|}{ Absolute $\triangle M D(d B)$} \\
\hline & 0.28 & 0.16 & 0.16 & 0.05 & 0.03 \\
\hline$P$-value & 0.00 & 0.00 & 0.00 & NS & NS \\
\hline \multicolumn{6}{|l|}{$\triangle P S D$} \\
\hline$r$ & 0.07 & 0.07 & 0.09 & 0.12 & 0.09 \\
\hline$P$-value & NS & NS & NS & NS & NS \\
\hline \multicolumn{6}{|c|}{ Absolute $\triangle P S D$} \\
\hline & 0.26 & 0.11 & 0.14 & 0.06 & 0.04 \\
\hline$P$-value & 0.000 & 0.02 & 0.011 & NS & NS \\
\hline
\end{tabular}

Abbreviations: Abs, absolute value; CCT, central corneal thickness; CDR, cup/disc area ratio; $\Delta$, difference; IOP, intraocular pressure; MD, mean deviation; PSD, pattern SD. 
there was not a linear distribution between CCT and damage, because of the distribution of the data. In particular when the subgroups were analysed, the subgroup with a greater $\Delta$ CCT $(>20 \mu \mathrm{m}$ ) showed a more significant difference between the eyes for VF indices and optic disc parameter (Table 3), but in this group no significant correlation between $\triangle \mathrm{CCT}$ and the other parameters was found, suggesting that the difference in CCT were not correlated to the amount of the functional and structural damage. However, only the $16 \%$ of the considered patients had a $\Delta$ CCT $>20 \mu \mathrm{m}$ between paired eyes, whereas $84 \%$ of the patients had a $\Delta \mathrm{CCT}<20 \mu \mathrm{m}$, $76 \%<15 \mu \mathrm{m}$ and $58 \%$ of the patients had a $\Delta \mathrm{CCT}$ $<10 \mu \mathrm{m}$. In the latter group, a very weak but significant correlation was found between absolute $\triangle \mathrm{CCT}$ and absolute $\triangle \mathrm{MD}$ and PSD. However, to have a $\Delta \mathrm{CCT}>20 \mu \mathrm{m}$ could be a risk factor for the thinner cornea eye for receiving a late diagnosis of glaucoma in that eye.

Part of these data agreed with Anand et al's ${ }^{29}$ study that showed that POAG patients with asymmetric VF damage had symmetric CCT values. Furthermore, they found that CCT measurements were highly symmetric in paired eyes in $>93 \%$ of the patients.

A possible bias of this study could be the presence of many centres involved, because of some subjective measurements (CDR or CCT measurement) that could change from one centre to another.

In conclusion, from these data most of the glaucomatous patients has a symmetric CCT and there is no correlation with the structural/functional damage; however, a difference in CCT measurements $>15 \mu \mathrm{m}$ between the two eyes had to be taken in consideration clinically: the thinner eye could be associated to a worse glaucoma.

\section{Summary}

\section{What was known before}

- Patients with thicker central corneal thickness has a higher measured intraocular pressure, whereas those with thinner central corneal thickness has a lower measured intraocular pressure.

What this study adds

- In this study, we found that about $18 \%$ of the glaucomatous patients have a difference in central corneal thickness $>20 \mu \mathrm{m}$, and the eyes with thinner central cornea have a worse visual field defect.

\section{Conflict of interest}

The authors declare no conflict of interest.

\section{Acknowledgements}

The IGR is grateful to AISG and SIGLA for their support.

\section{References}

1 Brandt JD, Beiser JA, Kass MA, Gordon MO. Central corneal thickness in the Ocular Hypertension Treatment Study (OHTS). Ophthalmology 2001; 108: 1779-1788.

2 Myrowitz EH, Kouzis AC, O'Brien TP. High interocular corneal symmetry in average simulated keratometry, central corneal thickness, and posterior elevation. Optom Vis Sci 2005; 82: 428-431.

3 Hahn S, Azen S, Ying-Lai M, Varma R. Central corneal thickness in Latinos. Invest Ophthalmol Vis Sci 2003; 44: 15081512.

4 Gordon MO, Beiser JA, Brandt JD, Heuer DK, Higginbotham EJ, Jonnson CA et al. The Ocular Hypertension Treatment Study: baseline factors that predict the onset of primary open-angle glaucoma. Arch Ophthalmol 2002; 120: 714-720.

5 Medeiros FA, Sample PA, Zangwill LM, Bowd C, Aihara M, Weinreb RN. Corneal thickness as a risk factor for visual field loss in patients with preperimetric glaucomatous optic neuropathy. Am J Ophthalmol 2003; 136: 805-813.

6 Herndon LW, Weizer JS, Stinnett SS. Central corneal thickness as a risk factor for advanced glaucoma damage. Arch Ophthalmol 2004; 122: 17-21.

7 Jonas JB, Stroux A, Velten I, Juenemann A, Martus P, Budde WM. Central corneal thickness correlated with glaucoma damage and rate of progression. Invest Ophthalmol Vis Sci 2005; 46: 1269-1274.

8 Sullivan-Mee M, Halverson KD, Saxon GB, Saxon MC, Shafer KM, Sterling JA et al. The relationship between central corneal thickness-adjusted intraocular pressure and glaucomatous visual-field loss. Optometry 2005; 76: 228-238.

9 Poinoosawmy D, Fontana L, Wu JX, Bruce CV, Hitchings RA. Frequency of asymmetric visual field defects in normaltension and high-tension glaucoma. Ophthalmology 1998; 105: 988-991.

10 Chen PP. Correlation of visual field progression between eyes in patients with open-angle glaucoma. Ophthalmology 2002; 109: 2093-2099.

11 Sullivan-Mee M, Gentry JM, Qualls C. Relationship between symmetric central corneal thickness and glaucomatous visual field loss within the same patient. Optom Vis Sci 2006; 83: $516-519$.

12 Sullivan-Mee M, Halverson KD, Qualls C. Clinical comparison of Pascal dynamic contour tonometry and Goldmann applanation tonometry in asymmetric openangle glaucoma. J Glaucoma 2007; 16: 694-699.

13 European Glaucoma Society. Terminology and Guidelines for Glaucoma, European Glaucoma Society. II ed. Vol 1.1, Dogma: Savona, 2003, pp 1-3.

14 Varma R, Tielsch JM, Quigley HA, Hilton SC, Katz J, Spaeth GL et al. Race-, age-, gender-, and refractive error-related differences in the normal optic disc. Arch Ophthalmol 1994; 112: 1068-1076.

15 Pederson JE, Anderson DR. The mode of progressive disc cupping in ocular hypertension and glaucoma. Arch Ophthalmol 1980; 98: 490-495.

16 Tuulonen A, Airaksinen PJ. Initial glaucomatous optic disk and retinal nerve fiber layer abnormalities and their progression. Am J Ophthalmol 1991; 111: 485-490.

17 Zeyen TG, Caprioli J. Progression of disc and field damage in early glaucoma. Arch Ophthalmol 1993; 111: 62-65. 
18 Yablonski ME, Zimmerman TJ, Kass MA, Becker B. Prognostic significance of optic disk cupping in ocular hypertensive patients. Am J Ophthalmol 1980; 89: 585-592.

19 Tholen A, Tremmel L, Maurer W, Robert Y, Hendrickson P. Lateral differences indicate future glaucoma. Graefes Arch Clin Exp Ophthalmol 1992; 230: 29-35.

20 Kitazawa Y, Horie T, Aoki S, Suzuki M, Nishioka K. Untreated ocular hypertension. A long-term prospective study. Arch Ophthalmol 1977; 95: 1180-1184.

21 Iester M, Mermoud A. Retinal nerve fiber layer and physiological central corneal thickness. J Glaucoma 2001; 10: 158-162.

22 Jonas JB, Holbach L. Central corneal thickness and thickness of the lamina cribrosa in human eyes. Invest Ophthalmol Vis Sci 2005; 46: 1275-1279.

23 Kim WJ, Chen PP. Central corneal pachymetry and visual field progression in patients with open-angle glaucoma. Ophthalmology 2004; 111: 2126-2132.

24 Chauhan BC, Hutchison DM, LeBlanc RP, Artes PH, Nicolela MT. Central corneal thickness and progression of the visual field and optic disc in glaucoma. $\mathrm{Br} J$ Ophthalmol 2005; 89: 1008-1012.

25 Iester M, Mete M, Figus M, Frezzotti P. Incorporating corneal pachymetry into the management of glaucoma. J Cataract Refract Surg 2009; 35: 1623-1628.

26 Congdon NG, Broman AT, Bandeen-Roche K, Grover D, Quigley HA. Central corneal thickness and corneal hysteresis associated with glaucoma damage. Am J Ophthalmol 2006; 141: 868-875.

27 Kida T, Liu JHK, Weinreb RN. Effect of 24-hour corneal biomechanical changes on intraocular pressure measurement. Invest Ophthalmol Vis Sci 2006; 47: 4422-4426.

28 Fogagnolo P, Rossetti L, Mazzolani F, Orzalesi N. Circardian variations in central thickness and intraocular pressure in patients with glaucoma. Br J Ophthalmol 2006; 90: 24-28.
29 Anand A, De Moraes CG, Teng CC, Tello C, Liebmann JM, Ritch R. Corneal hysteresis and visual field asymmetry in open angle glaucoma. Invest Ophthalmol Vis Sci 2010; 51: 6514-6518.

\section{Appendix}

The Italian Glaucoma Register:

M Iester ${ }^{1}$, P Brusini ${ }^{2}$, P Frezzotti ${ }^{3}$, GL Manni ${ }^{4}$, D Paoli ${ }^{5}$, M Rolando ${ }^{1}$, T Rolle ${ }^{6}, \mathrm{M} \mathrm{Uva}^{7}$, $\mathrm{R}$ Altafini ${ }^{8}$, M Figus ${ }^{9}$, E Martini $^{10}$, G Milano ${ }^{11}$, A Perdicchi ${ }^{12}$, L Rossetti ${ }^{13}$, P Fogagnolo $^{13}$, A Rossi ${ }^{14}$, G Rossi ${ }^{11}$, F Scrimieri ${ }^{15}$, M Vetrugno ${ }^{16}$

${ }^{1}$ Laboratorio clinico anatomo-funzionale per la diagnosi e il trattamento del glaucoma e delle malattie neurooftalmologiche, Clinica Oculistica, Department of Neurological Sciences, Ophthalmology, Genetic, University of Genoa, Italy, ${ }^{2}$ Divisione di Oculistica, Ospedale di Udine, ${ }^{3}$ Clinica Oculistica, University of Siena, ${ }^{4}$ Clinica Oculistica, University Tor Vergata, Rome, ${ }^{5}$ Divisione di Oculistica, Ospedale di Monfalcone, ${ }^{6}$ Clinica Oculistica, University of Torino, ${ }^{7} \mathrm{Clinica}$ Oculistica, University of Catania, ${ }^{8}$ Divisione di Oculistica, Ospedale di Bassano, ${ }^{9}$ Divisione di Oculistica, Ospedale di Sassuolo, ${ }^{10}$ Clinica Oculistica, University of Pisa, ${ }^{11} \mathrm{Clinica}$ Oculistica, University of Pavia, ${ }^{12}$ Clinica Oculistica, University of La Sapienza II, Rome, ${ }^{13}$ Clinica Oculistica, San Paolo, University of Milan, ${ }^{14}$ Clinica Oculistica, University of Milan, ${ }^{15}$ Divisione di Oculistica, Ospedale di Tricase, ${ }^{16}$ Clinica Oculistica, University of Bari 